\title{
RESULTS OF VIDEO-ASSISTED THYMECTOMY IN PATIENTS WITH MYASTHENIA GRAVIS
}

Michael J. Mack, MD

Rodney J. Landreneau, $\mathrm{MD}^{\mathrm{b}}$

Anthony P. Yim, $\mathrm{MD}^{\mathrm{c}}$

Steven R. Hazelrigg, $\mathrm{MD}^{\mathrm{d}}$

Granger R. Scruggs ${ }^{\text {a }}$
Objective: The efficacy of video-assisted thoracic surgery for thymectomy with myasthenia gravis has not been examined. Methods: Thirty-three consecutive patients underwent total thymectomy by video-assisted techniques between 1992 and 1995 . There were 13 male and 20 female patients with a mean age of $38.42 \pm 16.88$ years (range 9 to 84 years). The procedures were performed by either a right $(n=11)$ or left $(n=22)$ thoracoscopic approach and all anterior mediastinal tissue was removed. Results: There was no perioperative mortality or long-term morbidity. One patient required conversion of the video-assisted thechnque to a lateral thoracotomy. All patients except one were extubated immediately. The mean hospital stay was $4.12 \pm 6.07$ days (range 1 to 37 days) with a median of 3 days. Mean follow-up is $23.39 \pm 11.72$ months (range 4 to 47 months). Clinical improvement was seen in $87.9 \%(29 / 33)$ : one of two patients $(50 \%)$ in stage I, 17 of $19(89.4 \%)$ in stage IIA, eight of nine $(88.8 \%)$ in stage IIB, and three of three $(100 \%)$ in stage III. Metaanalysis of these results compared with results in nine published series in which other techniques were used showed no difference in clinical improvement after thymectomy between series. Conclusion: We conclude that video-assisted thymectomy is as effective as the traditional open surgical approaches for performance of thymectomy in the management of patients with myasthenia gravis. In addition, the improved cosmesis of the video-assisted approach ideally will lead to earlier thymectomy in patients with myasthenia gravis. ( $J$ Thorac Cardiovasc Surg 1996;112:1352-60)
$\mathrm{M}$ yasthenia gravis is a chronic autoimmune disorder in which surgical thymectomy has been demonstrated to have a positive effect on the course of the disease in most patients. Complete removal of all thymic tissue is believed to be necessary to maximize the surgical results. ${ }^{1}$ Standard surgical approaches include the transsternal, transcervical,

From Columbia Hospital at Medical City Dallas, Dallas, Tex., ${ }^{a}$ Allegheny General Hospital, Pittsburgh, Pa., ${ }^{b}$ The Chinese University of Hong Kong, Shatin, N.T., Hong Kong, ${ }^{c}$ and Southern Illinois University-School of Medicine, Springfield, Ill. $^{\mathrm{d}}$

Read at the Seventy-sixth Annual Meeting of The American Association for Thoracic Surgery, San Diego, Calif., April 28-May 1, 1996.

Received for publication May 3, 1996; revisions requested June 10, 1996; revisions received July 12, 1996; accepted for publication July 15, 1996.

Address for reprints: Michael J. Mack, MD, Cardiothoracic Surgery Associates of North Texas P.A., 7777 Forest Lane, Suite 323-A, Dallas, TX 75230.

Copyright @ 1996 by Mosby-Year Book, Inc.

0022-5223/96 $\$ 5.00+0 \quad \mathbf{1 2 / 6 / 7 6 5 0 9}$ and the "maximal" thymectomy, which combines the transsternal and transcervical approaches. ${ }^{2-4}$ All of these procedures have demonstrated efficacy.

The role of video-assisted thoracic surgery (VATS) has been well defined for the management of a number of diseases. ${ }^{5}$ For many medical problems such as the treatment of malignant pleural effusions, lung biopsy, and spontaneous pneumothorax, the benefits of the procedure are immediate and obvious and are adequately evaluated by short-term follow up. ${ }^{6-8}$ However, for other diseases in which the course is variable and the results of an intervention are not immediately apparent, such as myasthenia gravis, a longer period of follow-up is necessary before the procedure can be assessed. ${ }^{9}$ Although the ability to technically perform a thymectomy by the less invasive VATS technique was immediately apparent, the efficacy of the procedure in comparison with accepted standards required long-term followup. ${ }^{10}$ The purpose of this study is to evaluate the efficacy of the VATS approach for thymectomy by intermediate-term results and to compare those results with published standard results. 


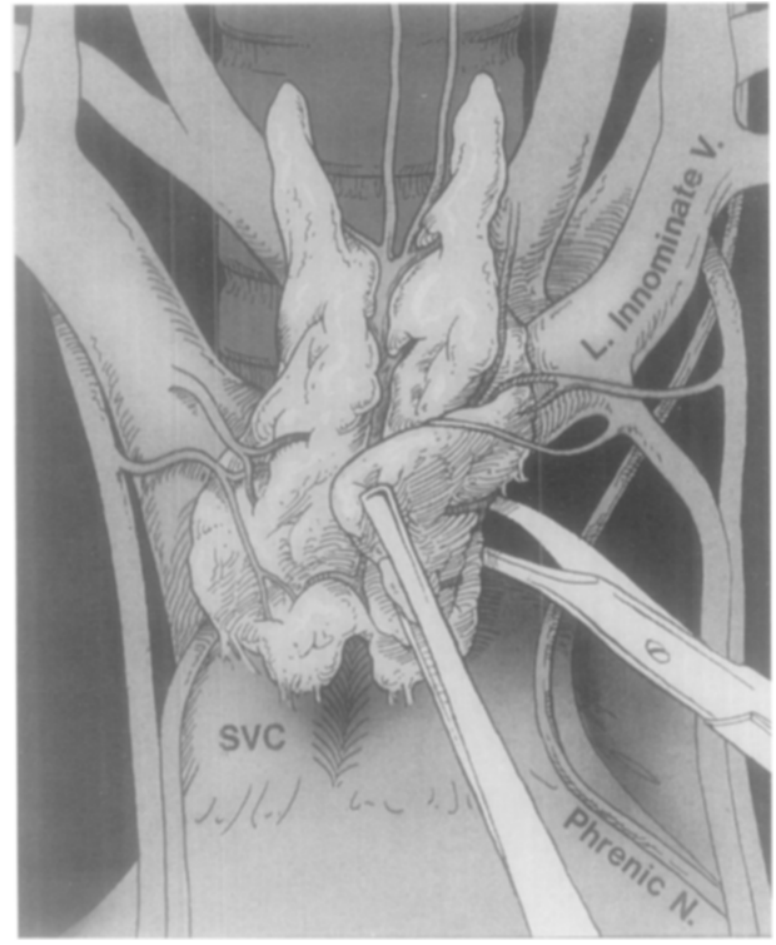

Fig. 1. Thymic dissection by the VATS approach is started at the inferior pole of the gland anterior to the phrenic nerve. $S V C$, Superior vena cava.

\section{Patients and methods}

Thirty-three patients underwent VATS thymectomy at four participating institutions between March 1992 and October 1995. These institutions were Columbia Hospital at Medical City Dallas, Dallas, Texas (13 patients), Prince of Wales Hospital, Hong Kong (10 patients), University of Pittsburgh, Pittsburgh, Pennsylvania (6 patients), and St. Luke's Hospital, Milwaukee, Wisconsin (4 patients). The thoracic surgeons at each institution had already gained significant VATS experience with technically more simple procedures before embarking on this study. All patients gave informed consent after being apprised of the variables, which included the unproven nature of the VATS approach and the possibility of conversion to an open approach if safety or the ability to perform a complete thymectomy was in doubt. They were also offered the option of the more standard approaches.

In all patients myasthenia gravis was confirmed by clinical features as well as by one or more of the following: electromyographic studies, edrophonium chloride (Tensilon) test, and circulating acetylcholine receptor antibody studies. A computed tomogram was obtained on all patients. No specific preoperative preparation or optimization regimen including plasmapheresis was performed. All patients with myasthenia gravis were included in this series, including those patients who had thymomas.

Surgical technique. The VATS procedure is performed with the patient under general endotracheal anesthesia with a double-lumen tube to effect ipsilateral lung col-

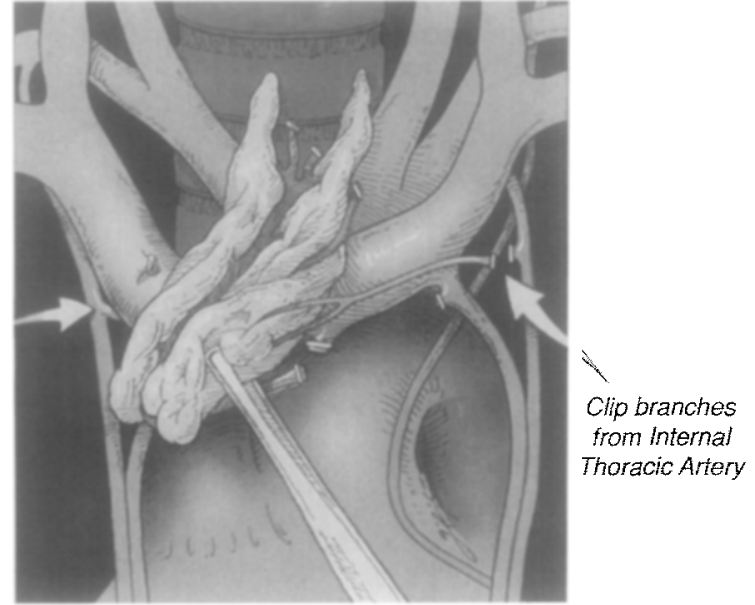

Fig. 2. The arterial blood supply to the thymic gland arising from the internal thoracic artery is ligated with clips and divided.

lapse. A left-sided tube is used in all patients. The patient is placed at a 30-degree angle from horizontal by a roll placed under the back on the side through which the thymus is being approached. Three $10 \mathrm{~mm}$ incisions are made in either the right or left infraaxillary area depending on which side of the chest is to be entered. A 30-degree angled telescope is placed through the middle incision and the grasping instrument and scissors through the lateral ones. With the use of standard endoscopic instruments including a tissue-grasping forceps and endoscopic scissors, the dissection is begun at the inferior portion of the thymic gland just anterior to the phrenic nerve (Fig. 1). By a combination of sharp and blunt dissection, all anterior mediastinal tissue is teased off the pericardium. The mediastinal pleura is then divided in the retrosternal area and the anterior portion of the thymic gland is dissected from the retrosternal area. The arterial blood supply to the thymic gland that arises from the internal thoracic artery is next ligated with endoscopic clips (Fig. 2). At this point the innominate vein can be identified. Dissection is carried carefully along the innominate vein until the thymic branches entering the innominate vein are identified and also divided with an endoscopic clip (Fig. 3). Next, the gland is dissected off the contralateral pleura. This is done by blunt dissection so that the contralateral phrenic nerve is not injured. Once the gland is mobilized to this point, it is often helpful to introduce a fan retractor or other instrument to retract the bulk of thymic tissue out of the way so that dissection into the cervical area can continue. Finally, dissection is carried cephalad to the innominate vein until the superior horns of the thymic gland are identified. The fascial attachments of the thymic gland to the inferior portion of the thyroid gland are divided. The most difficult area to access and visualize is the recess between the superior vena cava-innominate vein junction. For this reason we have frequently found it easier to visualize this area through the right thoracoscopic approach. We have also found that the 30 -degree telescope significantly aids visu- 


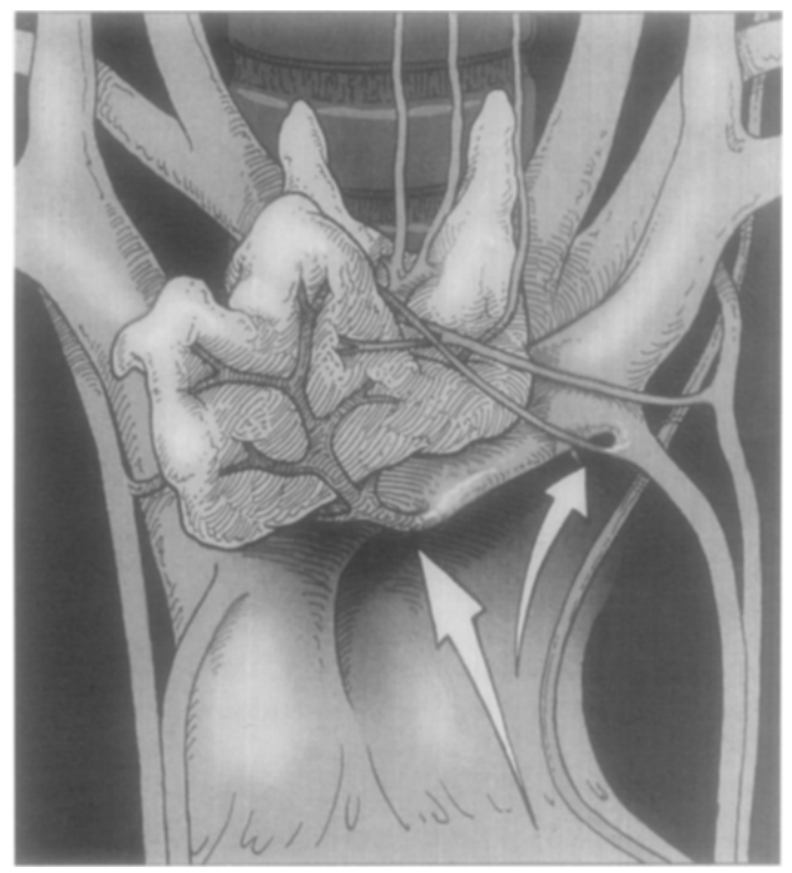

\section{Clip branches to Innominate Vein}

Fig. 3. After identification of the innominate vein, the thymic branches are clipped and divided.

alization, especially when the dissection is above the innominate vein into the cervical area.

When the dissection of the thymic gland is complete including the cervical area, the tissue is removed through an anterior trocar site (Fig. 4). We routinely place the tissue in a specimen bag, which allows easier extraction of tissue, without fragmentation. It also obviates the concern of potential seeding of the chest wall if a thymoma is present in the specimen. Hemostasis is obtained and the lung is reinflated. A chest tube or drain is not routinely used. The incisions are closed with a subcuticular suture.

The patients are extubated in the operating room. After a period of observation in the recovery room, they are returned to a thoracic surgical floor. The preoperative medications including anticholinergic drugs and frequently steroids are restarted at their preoperative doses. After an initial period of stabilization after the operation, if the patient is receiving steroids, the medication is gradually tapered over a 4- to 6-month period. Anticholinergic medication is then slowly tapered over the ensuing 4 to 6 months.

Statistical analysis. The association between surgical outcome and a series of preoperative patient and clinical variables in this series was assessed by means of $\chi^{2}$, Fisher's exact test, and Kendall's $\tau$ as appropriate. All statistical procedures were performed with the use of SAS version 6.06 (SAS Institute, Inc., Cary, N.C.) on an IBM-compatible computer. Results were considered significant if the observed probability was less than 0.05 . The

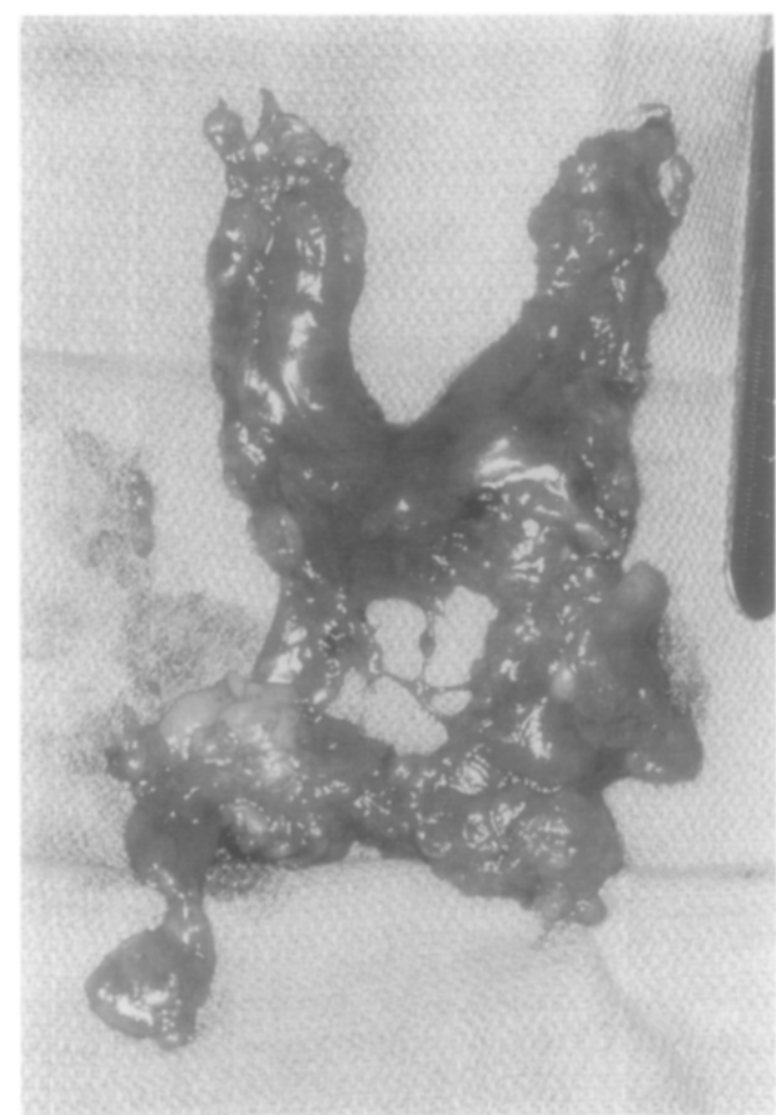

Fig. 4. Typical thymus specimen after VATS dissection. Removal of all anterior mediastinal tissue in addition to the thymic gland is demonstrated.

variables examined included duration of symptoms, sex, age, preoperative Osserman classification, and pathology. Contingency tables were evaluated by $\chi^{2}$ and Fisher's exact tests.

\section{Results}

The results of 33 consecutive thymectomies performed at four institutions by means of VATS between March 1992 and October 1995 are listed in Table I. The severity of preoperative disease was graded by means of the Osserman classification ${ }^{11}$ (Table II). Surgical outcome was scored following the criteria used by DeFilippi, Richman, and Ferguson $^{12}$ (Table III).

The study population consisted of 20 female and 13 male patients. The mean age was $38 \pm 16.9$ years (range 9 to 84 years) with a mean duration of symptoms of $16 \pm 12.9$ months (range 2 to 48 months) (Table IV). Twenty-two procedures were performed through the left side of the chest and 11 through the right side. Intraoperative bleeding from 
Table I. Results of VATS thymectomy for myasthenia gravis

\begin{tabular}{|c|c|c|c|c|c|c|c|c|}
\hline Patient & Age, sex & $\begin{array}{c}\text { Duration of } \\
\text { preop. symptoms } \\
(\mathrm{mo})\end{array}$ & $\begin{array}{c}\text { Postop. } \\
\text { hospital stay } \\
\text { (days) }\end{array}$ & Pathology & $\begin{array}{c}\text { Follow-up } \\
\text { (mo) }\end{array}$ & $\begin{array}{c}\text { Preop. } \\
\text { classification } \\
\text { (Osserman) }\end{array}$ & $\begin{array}{c}\text { Postop. } \\
\text { classification } \\
\text { (DeFilippi) }\end{array}$ & $\begin{array}{c}\text { Steroids } \\
\text { preop./weaned }\end{array}$ \\
\hline 1 & $27, \mathrm{~F}$ & 48 & 2 & Hyperplasia & 47 & 2 & 1 & $\mathrm{No} /-$ \\
\hline 2 & $58, \mathrm{~F}$ & 2 & 3 & Thymoma & 46 & 2 & 2 & $\mathrm{No} /-$ \\
\hline 3 & $23, F$ & 15 & 3 & Hyperplasia & 42 & 2 & 3 & $\mathrm{No} /-$ \\
\hline 4 & $59, \mathrm{M}$ & 48 & 2 & Atrophic & 37 & 2 & 4 & Yes/no \\
\hline 5 & $32, \mathrm{M}$ & 6 & 3 & Hyperplasia & 34 & 2 & 3 & Yes/yes \\
\hline 6 & $32, F$ & 2 & 3 & Thymoma & 33 & 3 & 3 & Yes/no \\
\hline 7 & $48, F$ & 12 & 1 & Hyperplasia & 29 & 2 & 2 & $\mathrm{No} /-$ \\
\hline 8 & $32, \mathrm{~F}$ & 5 & 1 & Normal & 26 & 2 & 1 & Yes/yes \\
\hline 9 & $37, \mathrm{M}$ & 6 & 1 & Normal & 22 & 2 & 2 & $\mathrm{No} /-$ \\
\hline 10 & $45, \mathrm{M}$ & 6 & 5 & Thymoma & 14 & 2 & 3 & No/- \\
\hline 11 & $39, \mathrm{M}$ & 8 & 5 & Thymoma & 25 & 2 & 2 & Yes/yes \\
\hline 12 & $9, \mathrm{M}$ & 17 & 3 & Hyperplasia & 23 & 2 & 2 & Yes/yes \\
\hline 13 & $29, \mathrm{~F}$ & 22 & 37 & Hyperplasia & 22 & 3 & 2 & Yes/yes \\
\hline 14 & $52, \mathrm{M}$ & 14 & 3 & Thymoma & 21 & 2 & 2 & Yes/yes \\
\hline 15 & $34, \mathrm{~F}$ & 15 & 5 & Normal & 19 & 2 & 2 & $\mathrm{No} /-$ \\
\hline 16 & $76, \mathrm{M}$ & 12 & 5 & Thymoma & 15 & 2 & 3 & $\mathrm{No} /-$ \\
\hline 17 & $31, \mathrm{~F}$ & 10 & 4 & Normal & 18 & 2 & 2 & $\mathrm{No} /-$ \\
\hline 18 & $29, F$ & 16 & 5 & Normal & 17 & 3 & 2 & Yes/yes \\
\hline 19 & $75, \mathrm{M}$ & 9 & 2 & Normal & 14 & 2 & 3 & $\mathrm{No} /-$ \\
\hline 20 & $17, \mathrm{M}$ & 20 & 2 & Hyperplasia & 13 & 1 & 4 & Yes/no \\
\hline 21 & $25, \mathrm{~F}$ & 13 & 3 & Hyperplasia & 22 & 2 & 4 & Yes/no \\
\hline 22 & $39, \mathrm{~F}$ & 7 & 5 & Hyperplasia & 9 & 2 & 3 & Yes/yes \\
\hline 23 & $38, \mathrm{~F}$ & 9 & 5 & Hyperplasia & 24 & 2 & 2 & Yes/yes \\
\hline 24 & $84, \mathrm{M}$ & 6 & 3 & Atrophic & 7 & 2 & 2 & $\mathrm{No} /-$ \\
\hline 25 & $33, \mathrm{~F}$ & 5 & 5 & Hyperplasia & 28 & 2 & 3 & Yes/no \\
\hline 26 & $32, \mathrm{~F}$ & 7 & 2 & Hyperplasia & 12 & 1 & 1 & Yes/yes \\
\hline 27 & $52, \mathrm{M}$ & 30 & 5 & Hyperplasia & 34 & 2 & 4 & Yes/no \\
\hline 28 & $42, \mathrm{M}$ & 36 & 3 & Hyperplasia & 37 & 2 & 1 & $\mathrm{No} /-$ \\
\hline 29 & $30, F$ & 18 & 2 & Hyperplasia & 35 & 2 & 1 & No/- \\
\hline 30 & $33, F$ & 9 & 2 & Hyperplasia & 31 & 2 & 1 & Yes/yes \\
\hline 31 & $24, \mathrm{~F}$ & 48 & 1 & Hyperplasia & 6 & 2 & 2 & $\mathrm{No} /-$ \\
\hline 32 & $22, F$ & 24 & 1 & Hyperplasia & 6 & 2 & 3 & Yes/no \\
\hline 33 & $30, \mathrm{~F}$ & 24 & 4 & Hyperplasia & 4 & 2 & 3 & $\mathrm{No} /-$ \\
\hline
\end{tabular}

a thymic vein occurred in one patient early in our experience and required a limited lateral thoracotomy to control. All other patients were extubated in the operating room except for one patient with Down's syndrome who subsequently had postoperative pneumonia and required prolonged ventilation. No other intraoperative or postoperative complications occurred. Specifically, there were no instances of phrenic or recurrent nerve injuries, wound infections, or hypocalcemia. In no instance did the surgeon believe that conversion to an open approach was necessary to remove all thymic tissue. There was no mortality. Care in the intensive care unit was not routinely required. The mean hospital stay was $4.12 \pm 6.07$ days (range 1 to 37 days), with a median stay of 3 days.

Six patients had thymoma, all of which were diagnosed before the operation by computed tomographic scan. There was no evidence of invasion by scan or during the operation, and all thymomas were classified as stage I by the Masaoka classification. ${ }^{13}$ There has been no recurrence of tumor in the six patients with thymoma.

Mean follow-up is $23.39 \pm 11.72$ months (range 4 to 47 months). Clinical improvement was seen in $87.9 \%$ (29/33) of patients: one of two (50\%) in stage I, 17 of $19(89.4 \%)$ in stage IIA, eight of nine $(88.8 \%)$ in stage IIB, and three of three $(100 \%)$ in stage III. Complete remission, that is, no symptoms and no medications, occurred in six patients $(18 \%)$. Four patients did not have a change in clinical status after thymectomy, and no patient had deterioration in clinical status.

Because of the small number of patients, multivariate analysis of factors was not feasible. Analysis 
Table II. Osserman classification of myasthenia gravis

\begin{tabular}{|c|c|}
\hline Stage & Description \\
\hline Stage I & $\begin{array}{l}\text { Occular myasthenia gravis: involvement of } \\
\text { extraocular muscles only }\end{array}$ \\
\hline Stage IIA & $\begin{array}{l}\text { Mild generalized myasthenia gravis: general- } \\
\text { ized weakness without respiratory muscle } \\
\text { involvement }\end{array}$ \\
\hline Stage IIB & $\begin{array}{l}\text { Moderately generalized myasthenia gravis: } \\
\text { significant manifestation of weakness with } \\
\text { exercise tolerance }\end{array}$ \\
\hline Stage III & $\begin{array}{l}\text { Acute fulminating myasthenia gravis: rapid } \\
\text { onset (within } 6 \text { months) of respiratory } \\
\text { muscle involvement }\end{array}$ \\
\hline Stage IV & $\begin{array}{l}\text { Late severe myasthenia gravis: progressive in } \\
\text { severity for } 2 \text { or more years }\end{array}$ \\
\hline
\end{tabular}

Table III. DeFilippi postoperative classification

\begin{tabular}{cl}
\hline Class & \multicolumn{1}{c}{ Description } \\
\hline 1 & Complete remission, no medications \\
2 & Asymptomatic, decreased medications \\
3 & $\begin{array}{l}\text { Improved, decreased symptoms or decreased } \\
\text { medications }\end{array}$ \\
4 & No change \\
5 & Worsening symptoms \\
\hline
\end{tabular}

Table IV. Results of VATS thymectomy

\begin{tabular}{lc}
\hline Mean duration of symptoms (mo) & $16 \pm 12.9$ \\
Mean length of stay (days) & $4.12 \pm 6.07$ \\
Mean follow-up (mo) & $23.39 \pm 11.72$ \\
Patients treated with preoperative & 18 of $33(54.5 \%)$ \\
$\quad$ steroids & 12 of $18(66.7 \%)$ \\
Patients weaned off steroids & \\
\hline
\end{tabular}

of the cross-tabulated data revealed no significant associations between the patient's sex and histologic features of the thymus and the preoperative grade or postoperative outcome (Tables V to VII). Furthermore, there was no correlation between the duration of the symptoms and the preoperative severity of the disease $(\tau=0.017, p=0.902)$ or between the length of follow-up and surgical outcome $(\tau=-0.159, p=0.245)$.

Comparisons with published outcomes. To assess the success of VATS thymectomy, we compared the surgical outcomes from the current series with outcomes reported elsewhere (Table VIII). Logistic analysis, using the SAS PROC CATMOD program, was performed to assess the relationship between treatment outcomes (complete remission or improvement) and surgical
Table V. Outcome in relationship to preoperative stage

\begin{tabular}{lcccc}
\hline & \multicolumn{4}{c}{ No. of patients } \\
\cline { 2 - 5 } $\begin{array}{c}\text { Preoperative } \\
\text { clinical stage }\end{array}$ & $\begin{array}{c}\text { Complete } \\
\text { remission }\end{array}$ & $\begin{array}{c}\text { Moderately } \\
\text { improved }\end{array}$ & $\begin{array}{c}\text { Mildly } \\
\text { improved }\end{array}$ & $\begin{array}{c}\text { No } \\
\text { improvement }\end{array}$ \\
\hline I $(n=2)$ & 1 & 0 & 0 & 1 \\
IIA $(n=19)$ & 4 & 10 & 3 & 2 \\
IIB $(n=9)$ & 1 & 1 & 6 & 1 \\
III $(n=3)$ & 0 & 2 & 1 & 0 \\
Total $(n=33)$ & 6 & 13 & 10 & 4 \\
\hline
\end{tabular}

Table VI. Sex of patients correlated with histologic tumor type

\begin{tabular}{lcccc}
\hline \multicolumn{1}{c}{ Sex } & Atrophic & Hyperplasia & Thymoma & Sex totals \\
\hline Male & 4 & 5 & 4 & 13 \\
Female & 4 & 14 & 2 & 20 \\
Histology totals & 8 & 19 & 6 & 33 \\
\hline
\end{tabular}

Table VII. Outcome according to histologic type

\begin{tabular}{lccc}
\hline Histology & $\begin{array}{c}\text { No. of } \\
\text { patients }\end{array}$ & $\begin{array}{c}\text { Complete } \\
\text { remission }\end{array}$ & $\begin{array}{c}\text { Total } \\
\text { improved }\end{array}$ \\
\hline Hyperplasia & 19 & 5 & 16 \\
Atrophic & 8 & 1 & 7 \\
Thymoma & 6 & 0 & 6 \\
Total & 33 & 6 & 29 \\
\hline
\end{tabular}

technique. Logistic analysis revealed a significant treatment effect for the proportion of patients having improved outcomes $\left(\chi^{2}=21.54, p=\right.$ 0.0001 ) but not for the proportion of patients having complete remission $\left(\chi^{2}=5.5, p=0.1385\right)$. Inspections of the analysis of the weighted least squares estimates revealed that the proportion of patients having improved outcomes after thymectomy was significantly lower when the operation was performed by the sternotomy approach $\left(\chi^{2}=\right.$ $7.35, p=0.0067)$ and significantly greater when performed by the combined sternotomy and transcervical approach $\left(\chi^{2}=12.49, p=0.0004\right)$.

As a final step, our outcomes were compared with those reported by DeFilippi, Richman, and Ferguson, ${ }^{12}$ whose outcome criteria were used in the current series. Analysis of the cross-tabulated data demonstrated that the surgical outcomes of the current series are not significantly different from those reported by DeFilippi and associates (percent in complete remission: $\chi^{2}=0.02, p=0.887$; percent improved: $\chi^{2}=679, p=0.41$ ). 
Table VIII. Comparison to published outcomes

\begin{tabular}{|c|c|c|c|c|}
\hline Series & Technique & $\begin{array}{c}\text { Mean follow-up } \\
\text { (mo) }\end{array}$ & $\begin{array}{c}\text { No. in } \\
\text { complete } \\
\text { remission }\end{array}$ & $\begin{array}{c}\text { No. } \\
\text { improved }\end{array}$ \\
\hline Jaretzki et al., ${ }^{1} 1988(n=95)$ & $\mathrm{TS}+\mathrm{TC}$ & 40 & $36(37.9 \%)$ & $88(92.6 \%)$ \\
\hline \multirow[t]{2}{*}{ Lennquist et al., ${ }^{14} 1990(n=30)$} & $\mathrm{TS}+\mathrm{TC}$ & 50 & $6(20 \%)$ & $29(96.7 \%)$ \\
\hline & Total TS + TC $(n=125)$ & & $42(33.6 \%)$ & $117(93.6 \%)$ \\
\hline Frist et al., ${ }^{2} 1994(n=46)$ & TS & 75 & $13(28.2 \%)$ & $40(87 \%)$ \\
\hline Hatton et al. ${ }^{15} 1989(n=52)$ & TS & 46 & $14(28 \%)$ & $30(57.7 \%)$ \\
\hline Nussbaum et al., ${ }^{15} 1992(n=48)$ & TS & 51 & $20(41.7 \%)$ & $45(93.8 \%)$ \\
\hline Mulder et al., ${ }^{17} 1989(n=84)$ & $\mathrm{TS}$ & 36 & $30(35.7 \%)$ & $67(79.8 \%)$ \\
\hline \multirow[t]{2}{*}{ Kay et al.. ${ }^{18} 1994(n=36)$} & TS & 49 & $12(24.5 \%)$ & $26(72.2 \%)$ \\
\hline & Total TS $(n=266)$ & & $89(33.5 \%)$ & $208(78.2 \%)$ \\
\hline Cooper et al., ${ }^{3} 1988(n=65)$ & $\mathrm{TC}$ & 41 (median) & $34(52.3 \%)$ & $62(95.4 \%)$ \\
\hline \multirow[t]{2}{*}{ DeFilippi et al., ${ }^{12} 1994(n=53)$} & $\mathrm{TC}$ & 51 & $9(17 \%)$ & $43(81.1 \%)$ \\
\hline & Total TC $(n=118)$ & & $43(36.4 \%)$ & $105(89 \%)$ \\
\hline Present study $(n=33)$ & VATS $(n=33)$ & 23 & $6(18.2 \%)$ & $29(87.9 \%)$ \\
\hline
\end{tabular}

$T S$, Transsternal; $T C$, transcervical; $T S+T C$, combined transsternal + transcervical.

\section{Discussion}

Myasthenia gravis is a chronic disease in which surgical thymectomy has been demonstrated to have a positive effect. Numerous techniques for performance of a thymectomy have been described and published, including the transsternal technique, the transcervical approach, and the "maximal" thymectomy by the combined transcervical and transthoracic approach. In this article we describe our results of VATS for the performance of thymectomy.

Minimal access does not mean minimal exposure. Despite the limited incisions necessary to perform a thymectomy by VATS, as with standard open approaches, wide exposure to all of the anterior mediastinum and cervical area is available. All anterior mediastinal tissue is totally removed because of the variability and location of thymic tissue. Moreover, the ability to completely dissect and remove the superior horns of the thymic gland into the cervical area is not compromised by this approach.

Although the VATS approach can be performed on either side, we believe that the right side is technically easier for a number of reasons. First, there is increased room in the right thoracic cavity allowing greater maneuverability of telescope and instrumentation. Second, the presence of the superior vena cava as an early landmark allows easier definition of the vascular structures and identification of the innominate vein during the course of the dissection. Finally, the recess at the junction between the superior vena cava and innominate vein is better visualized and defined from the right side. On the left side, this junction is the most difficult area in which to perform the dissection, whereas an ap- proach through the right side aids dissection in this area. Although we consider thymectomy to be an advanced VATS procedure, it has not been as technically difficult as some other VATS procedures such as lobectomy and esophageal procedures. Time and patience on the part of thoracic surgeon are required for orderly execution of the procedure. As we have gained experience, the average time of a VATS thymectomy has been reduced to approximately $1 \frac{1}{2}$ hours.

Complete thymectomy is believed to be necessary to achieve the maximal clinical benefit on the course of myasthenia gravis. However, the only way of gauging the effectiveness of the procedure is by clinical response. Because myasthenia gravis is a chronic disease of variable pattern, analyzing the benefit of the operation can be difficult. Published series contain heterogeneous groups of patients classified by different methods, and meaningful comparison can be difficult. Table VIII presents the results of nine published series of thymectomy for myasthenia gravis performed by various techniques. We have added the results of our series to this table for comparison. Accurate comparison among all series is difficult because different preoperative classifications are used in different series, including the Osterhuis, the Osserman, and the modified Osserman classifications. In addition, different grading systems for response to thymectomy are used so that, again, totally accurate comparison between series is extremely difficult. Therefore we have compared the percentage of patients who were improved by thymectomy between different series, as well as the percentage of patients who obtained a 


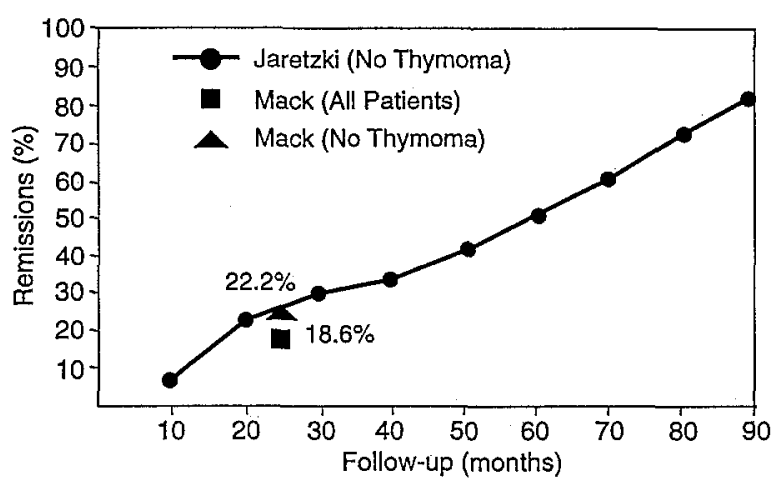

Fig. 5. Remission rate for myasthenia gravis.

complete remission, that is, free of symptoms and free of medications with thymectomy, by the different surgical techniques. Metaanalysis showed no difference in any single series in the percentage of patients with improvement. When clinical response was evaluated among combined series (Table VIII), the logistic analysis revealed that the proportion of patients having improved outcomes is significantly lower when thymectomy is performed by the sternotomy approach (78.2\%) and significantly greater when performed by the combined sternotomy and transcervical approach $(93.6 \%)$. However, in analysis of the combined approach series of Jaretzki and Wolff, ${ }^{4}$ only 95 of 123 consecutive thymectomies were analyzed. This omission of 28 patients makes meaningful analysis and interpretation of their results difficult. However, a lower complete response rate is shown in our series $(18.2 \%)$, as well as in the transcervical technique series by DeFilippi, Richman, and Ferguson ${ }^{12}(17 \%)$ compared with other series $(20 \%$ to $52 \%)$. Although this could be indicative of a less effective procedure, we believe that more likely it is a reflection of the relatively short duration of follow-up in our patients. The mean follow-up in our series is 23 months. Five of our patients who were operated on less than 1 year ago have received a significant benefit from thymectomy, but have not yet had a complete remission. In life-table analysis for attainment of complete remission in Jaretzki's series of patients without thymoma, the complete remission rate at 2 years was approximately $24 \%$, very similar to our present series (18.6\%) (Fig. 5). If we eliminate the patients with thymoma from our series; the complete remission rate improves to $22.2 \%$, the same as in
Jaretzki's series at the same length of follow-up. As we obtain longer follow-up times, we are optimistic that similar complete remission rates can be obtained by the VATS technique as by the other approaches.

Numerous preoperative variables have been described in the different series as predicting response to thymectomy. Shorter duration of symptoms, female sex, limited disease, more extensive disease, thymic hyperplasia, thymoma, and high titre acetylcholine antibody receptor levels have been described as positive prognostic factors predictive of surgical results. Analysis of our own series showed no difference in clinical response to thymectomy in any of the variables except for possibly classification IIA (see Table V). However, our series is too small to allow any meaningful conclusions.

The question may be raised as to why a thymectomy should be done by this approach. Despite statements in the standard management of myasthenia gravis that early thymectomy is best for results and is preferable to steroid therapy, this is not always clinical practice. As can be seen in our series, 18 of 33 patients $(54.5 \%)$ were receiving steroids before the operation, and thymectomy was therefore presumably delayed in these patients. Because a large proportion of patients with myasthenia gravis are young women, the undesirable cosmetic effect of the surgical approach is often a deterrent factor for early thymectomy and the option of steroids is chosen instead. It is hoped that the less invasive nature of the VATS procedure and the better cosmesis obtained will lead to earlier intervention in patients with myasthenia gravis.

In conclusion, the results of this series show that thymectomy by the VATS technique is as effective as other established surgical techniques in myasthenia gravis. The procedure is technically advanced. It should be undertaken by thoracic surgeons who have gained experience in simpler VATS procedures and have developed an interest and enthusiasm for the VATS approach. Because of the less invasive nature and superior cosmesis, it is hoped that patient and neurologist acceptance of thymectomy will increase and that referral for intervention will occur earlier in the course of the disease, when the response rate will be higher.

We acknowledge the contributions of Kevin M. Kelly, $\mathrm{PhD}$, for statistical analysis of the results and Pat Albers and Melba Harris for manuscript preparation. 


\section{REFERENCES}

1. Jaretzki A III, Penn AS, Younger DS, et al. "Maximal" thymectomy for myasthenia gravis: results. J Thorac Cardiovasc Surg 1988;95:747-57.

2. Frist WH, Thirumalai S, Doehring CB, et al. Thymectomy for the myasthenia gravis patient: factors influencing outcome. Ann Thorac Surg 1994;57:334-8.

3. Cooper JD, Al-Jilaihawa AN, Pearson FG, Humphrey JG, Humphrey HE. An improved technique to facilitate transcervical thymectomy for myasthenia gravis. Ann Thorac Surg 1988:45:242-7.

4. Jaretzki A III, Wolff M. "Maximal" thymectomy for myasthenia gravis: surgical anatomy and operative technique. J Thorac Cardiovasc Surg 1988;96:711-6.

5. Mack M, Aronoff RJ, Acuff TE, Douthit MB, Bowman RT, Ryan WH. The present role of thoracoscopy in the diagnosis and treatment of diseases of the chest. Ann Thorac Surg 1992;54:403-9.

6. Hartman DL, Gaither JM, Kesler KA, Mylet DM, Brown JW, Mathur PN. Comparison of insufflated talc under thoracoscopic guidance with standard tetracycline and bleomycin pleurodesis for control of malignant pleural effusions. J Thorac Cardiovasc Surg 1993;105:743-8.

7. Krasna MJ, White CS, Aisner SC, et al. The role of thoracoscopy in the diagnosis of interstitial lung disease. Ann Thorac Surg 1995;59:348-51.

8. Hazelrigg SR, Landreneau RJ, Mack M, Acuff TE, Seifert PE, Auer JE. Thoracoscopic stapled resection for spontaneous pneumothorax. J Thorac Cardiovasc Surg 1993;105:38993.

9. Drachman DB. Myasthenia gravis. N Engl J Med 1994;330: 1797-810.

10. Yim APC, Kay RLC, Ho JKS. Video assisted thoracoscopic thymectomy for myasthenia gravis. Chest 1995;108:1440-3.

11. Osserman KE, Genkins G. Studies in myasthenia gravis: review of a twenty year experience in over 1200 patients. J Mount Sinai Hosp 1971;38:497-537.

12. DeFilippi VJ, Richman DP, Ferguson MK. Transcervical thymectomy for myasthenia gravis. Ann Thorac Surg 1994; 57:194-7.

13. Masaoka A, Monden Y, Nakahara K, Tanioka T. Follow-up study of thymomas with special references to their clinical stages. Cancer 1981;48:2485.

14. Lennquist S, Andaker L, Lindvall B, Smeds S. Combined cervicothoracic approach in thymectomy for myasthenia gravis. Acta Chir Scand 1990;156:53-61.

15. Hatton PD, Diehl JT, Daly BDT, et al. Transsternal radical thymectomy for myasthenia gravis: a 15-year review. Ann Thorac Surg 1989;47:838-40.

16. Nussbaum MS, Rosenthal GJ, Samatha FJ, et al. Management of myasthenia gravis by extended thymectomy with anterior mediastinal dissection. Surgery 1992;112:681-8.

17. Mulder DG, Graves M, Hermann C. Thymectomy for myasthenia gravis: recent observations and comparisons with past experience. Ann Thorac Surg 1989;48:551-5.

18. Kay R, Lam S, Wong KS, Wang A, Ho J. Response to thymectomy in Chinese patients with myasthenia gravis. J Neurol Sci 1994;126:84-7.

\section{Discussion}

Dr. Paul A. Kirschner (New York, N.Y.). I have two comments. The first relates to the anatomic efficacy of thoracoscopic thymectomy per se. In the almost century-old history of thymectomy, the problem has always been "how to do it and how much to take out." The thoracoscopic method appears to me to be most comparable to the limited minimally invasive transcervical method and subject to its same shortcomings. Proponents of more radical methods such as thoracotomy, sternotomy (partial or complete), and various combined extended approaches all claim either "completeness" or "adequacy" of resection. These terms are not necessarily synonymous. Dr. Mack did not mention any search for or detection of ectopic thymic tissue in the mediastinal fat, accessibility to which is restricted by the limited exposure of thoracoscopy. Did it occur?

Also, the thoracoscopic method continues to mature, including as it does variable positions on the operating table (supine vs oblique vs lateral), location of ports (right, left, or bilateral), with or without a supplementary cervical incision. Dr. Mack has switched from a left-sided to a right-sided approach.

The second comment relates to the inclusion of the six thymomas in the clinical series of the 33 consecutive cases without detailed information such as histology or surgical stage. I presume that all were stage I completely encapsulated noninvasive thymomas. Could Dr. Mack kindly clarify that? He does not take into account either the unique nature of the myasthenia associated with thymomas as compared with that with nontumorous thymus (none of the six patients with thymomas had complete remission) or the unpredictable long-range prognosis of thymoma per se, however "benign" it may be pathologically.

Also, he makes no mention of the total patient pool from which these 33 cases were derived, nor does he indicate whether any patients were considered unsuitable for thoracoscopy for whatever reason, including those offered and refusing VATS.

Our first patient to undergo transcervical thymectomy in $1967^{1}$ had what we thought was an encapsulated thymoma. It recurred widely 8 years later, requiring extensive reoperation ${ }^{2}$ via sternotomy. This illustrates the necessity for long-range follow-up to establish the efficacy of a limited operation for even a stage I thymoma.

I would question the advisability of applying thoracoscopic thymectomy to thymoma, just as I do for transcervical thymectomy.

\section{REFERENCES}

1. Kirschner PA, Osserman KE, Kark AE. Studies in myasthenia gravis. Transcervical total thymectomy. JAMA 1969;209:906-10.

2. Kirschner PA. Reoperation for thymoma. Ann Thorac Surg 1990;49:550-6.

Dr. Mack. Thank you, Dr. Kirschner. Regarding the first point, limited access does not necessarily mean limited exposure. We believe that the VATS approach allows adequate visualization of all anterior mediastinal tissue and accessibility for removal. We are well aware of the potential presence of ectopic thymic tissue, and therefore all anterior mediastinal tissue is removed. In this series we saw no evidence of ectopic thymic tissue in the mediastinal fat.

Regarding the second issue of thymomas, all were encapsulated stage I thymomas in this series. All patients have been observed closely, and there is no evidence of 
recurrence, but we are well aware that follow-up is very short. We also believe that we performed the same procedure by the VATS approach that we would have by the open approach.

Dr. Joel D. Cooper (St. Louis, Mo.). I would argue that if you are going to do something less than a median sternotomy, the transcervical approach may in fact have some benefit: it gives bilateral exposure, does not necessitate going through the pleural spaces, and provides excellent exposure of the neck region. In the last 80 patients we have operated on over the past 5 years, half have gone home on the day after the operation, the mean and median hospital stay is less than 2 days, and the patients can return to work in several days. Furthermore, no chest tubes or drains are used. I would argue that this is as good a result as one is likely to achieve with any approach.

If you want to use a thoracoscope, you can put it in through the cervical incision and get a beautiful bilateral view, if you should choose to add that. I would be concerned about access to the aortopulmonary window area from a right-sided approach, which is one of the most difficult areas from which to remove ectopic thymic tissue. I would also argue that the best test of a complete thymectomy is the complete remission rate. As you said, your results will have to be viewed as tentative until you can demonstrate a better complete remission rate than you have achieved to date.
Finally, I would acknowledge that the disadvantage of the transcervical approach is perhaps a more steep learning curve. I might therefore suggest, somewhat tongue in cheek, that the VATS procedure might be one of the steps along that learning curve, after which you could graduate to a transcervical approach.

Dr. Mack. Thank you for your comments, Dr. Cooper. I find that the very similar arguments that we used for the VATS approach for thymectomy, as well as for all VATS procedures, were exactly those that Dr. Cooper voiced in discussion of his presentation of transcervical thymectomy in 1988.

Regarding comparison of this with a transcervical result, seven of the last 10 patients in our series have gone home the day after the operation. I think that as we gain more comfort with the care of these patients, the mean and median hospital stay will continue to become shorter. We are also aware of what Dr. Cooper mentioned about using the thoracoscope through the cervical incision to aid the lower part of the dissection, which is the most difficult by that approach. I believe the Toronto group is using that now for thymectomy.

We also are concerned about our low complete remission rate. However, five patients who are now 4 to 9 months postthymectomy appear to be on their way to complete remission. We hope that as our follow-up lengthens, equivalent complete remission rates will be obtained. 